\title{
A sociologia dos índices de sustentabilidade
}

\author{
Marina de Souza Sartore*
}

A crise financeira de 2008 alcançou proporção mundial, causando desconfiança no ambiente das práticas de investimento. Isso fica evidente pelo baixo desempenho dos mercados de ações de diversos países (cf. Twin, 2008). No entanto, apesar do certo descrédito de que as práticas de investimento foram alvo, as práticas de Investimentos Socialmente Responsáveis (ISRs) cresceram e mostraram-se como oportunidades de cooperação social voltada para reintegração e reformulação do mercado financeiro.

Essa potencialidade se explicita também no plano simbólico, pela fala do presidente-executivo da General Eletric, Jeffrey Immelt, a respeito da importância de aliar a responsabilidade social empresarial à busca de lucros para garantir a viabilidade da empresa a longo prazo. Em suas palavras, "Se a responsabilidade social das empresas está alinhada estrategicamente com os objetivos da empresa, ela nunca se torna algo superficial, nem redundante" (Immelt, 2008, p. 2). A declaração teve grande repercussão, tendo sido citada entre os profissionais que atuam com a responsabilidade social como salvação para os negócios, pois esse discurso ocorreu quando a bolha financeira havia estourado.

Segundo dados apresentados pelo Fórum de Investimento Social norte-americano, a quantidade de ativos negociados pela lógica do ISR cresceu de U\$639 bilhões, em 1995, para U\$2,71 trilhôes, em 2007 (cf. Social Investment Forum, 2007, p. 11). Na Europa, o estudo divulgado pela rede
* Agradeço ao Roberto Grün, Harry Makler e Christophe Yenkey pelos comentários precisos. Este artigo é a versão traduzida de trabalho apresentado na Society for the Advancement of Socio-Economics (Sase) em Paris, em 2009, quando recebeu o prêmio Travel Award. 
1. Segundo Lébaron, inspirado por Bourdieu: "O campo global do poder é um espaço onde agentes que possuem alto volume relativo de diferentes tipos de capitais competem e disputam entre si para determinar os seus valores" (Lébaron, 2008, p. 123). Eles competem pela prevalência de valores e linguagens no espaço social. da European Sustainable Investment Forum (Eurosif) aponta que o ativo em ISRs de treze países europeus cresceu de $€ 1,033$ trilhōes, em 2005, para $€ 2,665$ trilhões, em 2007 (cf. Eurosif, 2008, p. 10). No Brasil, os ativos em ISRs somam $\mathrm{R} \$ 1,13$ bilhão (cf. Valenti e Torres, 2010).

A falta de confiança que assombra o investimento mainstream pode ser substituída pela crença de que, ao considerar-se o desempenho econômico, social e ambiental da empresa como um todo, se realiza um investimento mais seguro a longo prazo. Notícias recentes sobre o licenciamento do Índice Dow Jones de Sustentabilidade para um fundo público norte-americano (ocorrido pela primeira vez em 2008) são exemplo e sinal do crescimento desse mercado (cf. Dow Jones, 2008).

Isso não quer dizer que os ISRs sejam o único meio para a recuperação dos mercados financeiros. Mas sim que essas práticas - que constroem uma nova linguagem financeira e são aceitas no campo global de $\operatorname{poder}^{1}-$ podem $^{2}$ constituir um dos caminhos para recompô-lo. Devido ao desenvolvimento do ISR torna-se necessário um estudo sobre a dinâmica sociológica desse subespaço das finanças.

Porém, como apreender essa "nova linguagem financeira"? Indo além, como encontrar elementos para desenvolver uma análise sociológica das mudanças da abordagem clássica (baseada em noções como "mão invisível”, "liberdade", homo economicus, "economia ortodoxa”) para outra baseada em noçôes de "mão visível”, "ética”, "públicos interessados", "economia heterodoxa"? Em suma, para a abordagem da chamada "responsabilidade social"?

Uma possibilidade é atentar para os profissionais que trabalham com os ISRs. Há muitos deles na Europa e nos Estados Unidos e esse mercado já existe também no Brasil. Sartore (2010) desenvolve estudo aprofundado sobre os profissionais que trabalham na interface das finanças e da sustentabilidade. Para fins deste artigo, exploro uma pequena amostra internacional de líderes atuantes nesse espaço.

Os conselhos dos índices de sustentabilidade dos mercados de açôes parecem ser o espaço social, por excelência, de circulação desses líderes. Nossa amostra compóe-se de conselhos relativos a quatro desses indicadores: Dow Jones Sustainability Index (DJSI) dos Estados Unidos, FTSE4Good da Inglaterra, Johannesburg Stock Exchange Socially Responsible Investment Index (JSE ISR) da África do Sul e o Índice de Sustentabilidade Empresarial (ISE) do Brasil. Eles foram escolhidos por seu status de "índices nacionais", pois são usados para medir a situação macroeconômica de um país. O DJSI é parte do Dow Jones Indexes, conjunto dos índices financeiros mais famo- 
sos e consultados no mundo. Para uma descrição mais detalhada sobre sua importância, ver o trabalho de Goede ([1971]* 2005). Os índices do FTSE têm o mesmo papel na sociedade inglesa. Nos países em desenvolvimento (África do Sul e Brasil), os índices estão localizados em suas bolsas de valores e também foram elaborados com um viés nacional.

Além desse caráter nacional, esses índices compõem esta pesquisa pelo fato de que um inspirou a criação do outro. Os conselhos, por sua vez, conferem-lhes face pública, ou seja, podem demonstrar diferenças culturais e institucionais entre países e elucidar questões sobre as regras sociais que cada país incorpora para criar o que Bourdieu e Boltanski denominam lieu neutre. Segundo esses autores, o arranjo social que pode ser chamado de lieu neutre é produzido por um "efeito de objetividade que resulta principalmente pela estrutura eclética do grupo: é um lugar onde pessoas advindas de diferentes fraçôes se encontram. Cada indivíduo do grupo pode ser visto como um lugar de encontro dado pela multiplicidade de posiçôes que ocupam no centro da classe dominante" (Bourdieu e Boltanski, 1976, p. 60).

Para Lébaron (2008), a estrutura apolítica, pluralística e independente de um partido corresponde à ideologia oficial de "colegiado", um lugar para reproduzir a ideologia dominante. Bourdieu e Boltanski utilizam essa expressão para mostrar que, quando pensamos na constituição da sociedade, embora ela se apresente como se fosse o resultado de um debate heterogêneo, este ocorre em um lugar de atores sociais dominantes que empregam linguagem também dominante.

Considerar os conselhos dos índices como lieu neutre implica na busca pela compreensão da lógica que transforma os interesses particulares de um grupo dominante em interesses neutros e nacionalmente reconhecidos ${ }^{2}$. Mas quais são os elementos necessários para formar tal arranjo nos conselhos que estipulam índices para o mercado financeiro? Tratam-se dos mesmos para os diferentes países em questão? Haverá diferenças ou similaridades entre eles? Quais são as regras sociológicas prevalecentes nesse subespaço que tem pretensões de se tornar o pensamento mainstream das finanças? ${ }^{3}$ O objetivo aqui é o de esboçar elementos que permitam compreender a lógica social inerente a esses conselhos e, assim, entender uma das possíveis reconfigurações do mundo financeiro a partir de uma representação social baseada nas ideias dominantes do que seja o ISR. O artigo está divido em três partes: a primeira contextualiza o nascimento da figura do investidor consciente; a segunda apresenta a metodologia utilizada para a análise da amostra e a terceira, sua análise sociológica.
* A data entre colchetes refere-se à edição original da obra. Ela é indicada na primeira vez que a obra é citada. Nas demais, indica-se somente a edição utilizada pelo autor [N. E.].

2. Para um estudo inspirador sobre essas questôes, ver a discussão de Lébaron (2008) a respeito dos conselhos de política dos bancos centrais, cuja neutralidade é construída pela orientação ortodoxa de seus membros.

3. Durante a Conferência do Triple Bottom Line Investing, em Paris, em 2007, entrevistei informalmente um analista financeiro brasileiro que trabalhava com os ISRs globais de um banco internacional. Ao falar sobre o crescimento desse mercado nos países em desenvolvimento, ele afirmou que tais investimentos ainda não eram o mainstream, embora houvesse a intenção de sê-lo algum dia. 


\section{0 nascimento do investidor consciente}

Como afirma Giamporcaro, a história contada a posteriori pode ser considerada como ferramenta de legitimação das práticas atuais do ISR, uma tentativa de enraizá-lo em um continuum cultural (cf. Giamporcaro, 2006, p. 60). Não por acaso, a pesquisa sobre a história do ISR identifica diferentes origens. Como se trata de um mercado em construção, os diferentes pontos de partida de sua história ficam mais evidentes principalmente quando retransmitidos e resumidos nos trabalhos acadêmicos que se consagram ao tema.

As origens do ISR remetem aos tempos bíblicos, quando as leis judaicas ditavam maneiras éticas de investir o dinheiro (cf. Giamporcaro, 2006). Outra referência pode ser o fundador da igreja metodista John Wesley, com seu sermão intitulado "The use of money", que também pregava princípios éticos para o uso do dinheiro. $\mathrm{O}$ ponto de partida mais citado pela literatura consultada, no entanto, localiza-se ainda no final do século XVIII, quando os quaker, com suas convicções religiosas, se recusaram a investir no setor de armamentos e de escravidão, culminando na criação dos primeiros fundos de investimentos éticos nos anos de 1920.

$\mathrm{O}$ The Pioneer Fund foi o primeiro fundo de investimento ético criado nos Estados Unidos, em 1928. Esse fundo não investia em empresas ligadas a bebidas, tabaco e pornografia, levando, assim, a que as igrejas "pudessem investir seus fundos no mercado financeiro de acordo com seus princípios éticos" (Déjean, 2005, p.21). Até a década de 1960, o movimento ficaria marginalizado, recuperando suas forças a partir da "tomada de consciência" na forma de movimentos sociais em prol do meio ambiente, dos direitos civis, dos direitos das mulheres e do movimento antiguerra que começavam a colocar em xeque a responsabilidade social das empresas (cf. Giamporcaro, 2006). O cenário político de final dos anos de 1960 e início da década seguinte, nos Estados Unidos, é marcado pela reivindicação estudantil para que as fundações de universidades não investissem em empresas ligadas à guerra do Vietnã (cf. Brito et al., 2005; Déjean, 2005) e pelo boicote econômico à África do Sul, devido ao regime do Apartheid (cf. Brito et al., 2005; Déjean, 2005; Giamporcaro, 2006). Nesse período, surgem o Pax Global Fund (criado pela igreja metodista em 1968) e o South Africa Safe Equity (Safe), de 1980, ambos com o intuito de reunir empresas que não tinham negócios na África do Sul (cf. Brito et al., 2005).

Também na década de 1980 afloram as preocupações com o meio ambiente, levando à elaboração dos fundos verdes (cf. Brito et al., 2005). 
Diferentemente de seus antecessores, os fundos verdes são baseados em um investimento crítico positivo - isto é, um investimento em empresas que desenvolvem ações para preservar o meio ambiente - e não na exclusão de setores que contrariam determinada postura ética. Ainda nessa área, a publicação de relatórios socioambientais e a criação de prêmios para as melhores empresas sustentáveis contribuíram com a construção de um olhar crítico positivo que, em vez de condenar as empresas por suas práticas negativas, as premia pelas boas práticas socioambientais. Assim, as empresas passam a aliar o desempenho socioambiental ao desempenho econômico (no intuito de agradar seus acionistas). Dentro dessa perspectiva, surge uma primeira distinção fundamental entre os ISRs éticos (baseados na exclusão de empresas) e os de performance (baseados na inclusão de empresas com melhores práticas de responsabilidade social). Esses investimentos são chamados de negative screening ou positive screening, respectivamente.

A partir desses índices (tanto os de exclusão, como os de performance) surgiram diversos estudos com o intuito de demonstrar ou de refutar a teoria de que as empresas socialmente responsáveis tendem a um desempenho financeiro melhor do que as empresas listadas nos índices considerados tradicionais, ou seja, que reúnem as empresas em sua carteira de investimentos considerando somente seus aspectos financeiros. O trabalho de Brito et al. (2005) sugere que, apesar dos diversos trabalhos acadêmicos que tentam averiguar se os índices de sustentabilidade têm melhor desempenho do que os índices convencionais, ainda não foi possível estabelecer consenso. No entanto, mais interessante que a investigação sobre o desempenho desses índices é o fato de que, a despeito de consenso sobre seus rendimentos, o mercado do ISR se desenvolveu, como ilustra o caso da Inglaterra, descrito por Gond (2006). O trabalho destaca o fato de que os mercados são constituídos pela crença compartilhada entre seus atores.

A crença de que as empresas socialmente responsáveis têm melhor rendimento criou seguidores e o corolário desta, o espaço do ISR, tornou-se parte de um movimento maior chamado "finanças sustentáveis". Esse movimento, por sua vez, adquiriu concretude pela elaboração dos Princípios para o Investimento Responsável (PRI) por parte da Organização das Nações Unidas, dos Princípios do Equador pelo Banco Mundial, pela criação de fundos de investimentos éticos ou sociais por parte dos bancos comerciais. O ISR constitui prática voltada para o mercado de capitais e faz parte do movimento maior de finanças sustentáveis que "diz respeito à atuação do sistema financeiro de forma economicamente viável, social- 
mente justa e ambientalmente correta" (Centro de Estudos de Sustentabilidade, 2010, s. p.).

\section{Metodologia}

O delineamento dos conselhos dos índices de sustentabilidade, tal como proposto por esta análise, diz respeito ao ano de 2008, momento da crise financeira mundial. Consulta às páginas eletrônicas dos conselhos de cada índice permite oferecer um retrato atualizado de cada um deles. Foram identificados 36 membros distribuídos da seguinte maneira: o Conselho do indicador brasileiro conta com nove membros, o DJSI, com cinco, e os FTSE4Good e JSE SRI, com onze cada um.

O conselho do FTSE4Good é composto, na verdade, por dezessete membros, mas seis deles participam como membros ex-officio, o que significa pertencer ao conselho por ocupar um cargo na instituição que pretence ao conselho e na maior parte das vezes, sem direito a voto. Em outras palavras, trata-se de um conselheiro empossado não por qualidades pessoais ou profissionais. Em eventual desligamento da primeira instituição, a substituição no conselho é automática. Isso pode levantar uma questão metodológica: devem esses seis indivíduos ser excluídos da amostra? Poder-se-ia argumentar que a posse do cargo é suficiente para considerá-los como membros importantes do conselho. Por outro lado, perspectiva adotada neste artigo, é possível entender que essa distinção interna é indicadora da diferença entre aqueles que são substituíveis (os que representam uma instituição) e aqueles que não o são (os que representam a si mesmos). Assim, dada essa distinção entre conselheiros permanentes e ex-officio, optou-se por excluir estes últimos da amostra e considerar apenas os conselheiros permanentes, privilegiando os capitais que detêm e investigando dados de suas biografias. Os conselhos dos índices podem ser vistos como um espaço social específico "onde diferentes tipos de capitais acumulados pelos indivíduos estão em disputa" (Lébaron, 2008, p. 123). O fato de que esses capitais são acumulados a partir das trajetórias dos indivíduos leva à análise de dados biográficos. A utilização de minibiografias permite o esboço dos conselhos como espaço social, pois,

[...] os acontecimentos biográficos se definem tanto pelas posiçôes ocupadas quanto pelas mudanças no espaço social, quer dizer, mais precisamente pelos diferentes estados sucessivos da estrutura de distribuição das diferentes espécies de capital que estão em jogo no campo considerado (Bourdieu, 1986, p. 71). 
Apesar da facilidade em encontrar os nomes dos conselheiros nas respectivas páginas eletrônicas, dados de trajetórias educacionais e profissionais impõem maior dificuldade. Foi necessário consultar diferentes fontes na internet para reunir esse tipo de informação. Importante ressaltar que temos ciência dos perigos que envolvem buscas na rede de computadores, especialmente no caso de dados que podem não refletir a realidade por já terem sido trabalhados pela mídia. Por esse motivo, o esforço foi de busca de informaçōes em minibiografias disponibilizadas pelos próprios conselheiros nos meios eletrônicos, ainda que nem todos o façam. Desse modo, vale a menção ao trabalho de Lébaron (2008) sobre os conselhos dos bancos centrais de diferentes países, no qual ele explica que, na impossibilidade de obtenção de dados por via direta, há que se considerar os dados disponíveis. Vale acrescentar que o próprio fato de que alguns tornem acessíveis informações de suas biografias, enquanto outros não o façam, pode apontar divisão entre os conselheiros que são independentes da exposição pública (provavelmente a reputação deles é inerente ao espaço social onde circulam) e aqueles que precisam desse tipo de exposição (provavelmente porque não têm os capitais necessários para pertencer ao círculo do conselho, precisando convertê-los em capitais reconhecíveis).

As origens desses índices podem variar, mas cada um pode ser considerado o corolário do outro. Enquanto o DJSI foi lançado em 1999 como resultado da cooperação entre Stoxx Ltd., Dow Jones Indexes Co. (consultorias em criação de índices para o mercado financeiro) e Sustainable Asset Management (Sam, empresa de gestão de ativos sustentáveis), o FTSE4Good foi lançado em 2001, pela FTSE, joint-venture composta entre o jornal Financial Times e a Bolsa de Valores de Londres. Inspirado por esses dois índices, a Bolsa de Valores de Joanesburgo cria, em 2004, o seu índice socialmente responsável que, por sua vez, inspirou a Bolsa de Valores de São Paulo, na criação da versão brasileira desse índice, o ISE.

Os arranjos por detrás da criação desses índices indicam que as instituições mais interessadas nos temas concernentes ao ISR são os bancos comerciais, os gestores de ativos, a mídia de negócios e os provedores de índices que pertencem à esfera privada. A maioria deles foi criada sem polêmicas, excetuando-se o indicador brasileiro, envolvido em um debate controverso e público a respeito de sua composição, metodologia e resultados. Sartore (2010) procura dar conta das controvérsias quando do lançamento do ISE, em 2005, no Brasil. 
4. Entrevista cedida a mim em 11 de dezembro de 2008, em São Paulo.

\section{Sobre os conselhos e seus conselheiros}

O Cise, conselho deliberativo responsável pelo ISE, ratifica a metodologia para seu cálculo - criada, por sua vez, pela Fundação Getúlio Vargas - e é responsável por sua ideologia. Buosi, analista de um fundo de investimento ético, afirma que "sem um comitê, a metodologia não é válida" ${ }^{4}$. O Cise é pretensamente composto por representantes de segmentos da sociedade (investidores, bancos de investimento, fundos de pensão) ou de temas de interesse social (meio ambiente, responsabilidade social corporativa, a governança corporativa).

Já o DJSI é gerido por dois conselhos: o Design Committee e o Advisory Committee. O primeiro é formado por dois profissionais da corporação Sam e dois da Dow Jones Indexes Co. sendo todos responsáveis por tarefas mais técnicas. O segundo é

[...] composto por profissionais do mercado financeiro independentes e por especialistas em desempenho empresarial sustentável. Reúne no máximo 10 pessoas para contribuírem com insights no campo da sustentabilidade e do investimento, com conselhos para as possíveis implicações das configuraçôes de carteiras sustentáveis e para colaborar com ideias sobre a metodologia, propaganda e desenvolvimento de produtos para os índices Dow Jones (DJSI, 2008, s.p.).

Ambos, DJSI e ISE, são divididos por um grupo técnico e uma face pública, constituída para dar legitimidade pública (nacional e internacional) para o índice.

De acordo com o FTSE,

A administração e a evolução da série de índices FTSE4Good está sob a direção de um conselho que é um corpo independente de especialistas advindos do campo da responsabilidade social, gestores de fundo, academia e a comunidade de negócios (FTSE, 2008, s.p.).

O conselho do JSE consiste em um "Um grupo de especialistas independentes cujo espectro inclui gestores de investimento, companhias listadas, especialistas em sustentabilidade, acadêmicos e representantes da sociedade civil" (JSE, 2008, s.p.).

Em uma primeira análise, parece não existir lógica social nos conselhos, devido à diversidade de instituições que deles participam: na verdade, é o 
efeito de lieu neutre que confere aos conselhos sua aparência de neutralidade e independência, tanto pela mencionada variedade de representatividade, quanto pelas presenças de "especialistas em desempenho de sustentabilidade empresarial", "de um conselho que é um corpo independente de especialistas" ou ainda de "um grupo de especialistas independentes", segundo as citaçôes mencionadas anteriormente. É interessante notar a necessidade de ser um especialista para participar desses conselhos. No entanto, existem poucas instituições que possibilitam a aquisição de capitais específicos para o espaço de interseção entre finanças e sustentabilidade. Sendo assim, importa compreender quais os capitais são mobilizados para designar um especialista neste espaço.

Ao analisar os 36 perfis, ou, mais especificamente, os discursos mobilizados por esses profissionais, aparecem quatro tipos de capital que orientam a definição do pertencimento a esse espaço social: trajetória profissional, trajetória educacional, capital social e capital simbólico.

A trajetória educacional varia em quatro modalidades. Três mais tradicionais: negócios (toda a educação obtida em negócios, economia, marketing e relações internacionais), biológicas (toda a educação adquirida por meio das ciências naturais, biologia, geologia) e humanidades (direito, ciências sociais e estudos políticos). Os formados na área de negócios são considerados insiders, enquanto os provenientes da biologia e das humanidades são considerados outsiders. Por fim, há as trajetórias educacionais na área de sustentabilidade (o contexto educacional que combina duas trajetórias distintas, como, por exemplo, direito e meio ambiente). Esta última é relativamente nova por ser o resultado de uma demanda recente por profissionais que reúnem duas disciplinas: uma relacionada com negócios e outra com ética, meio ambiente ou algo similar.

A trajetória profissional é definida pelas instituições pelas quais os indivíduos passaram: de um lado, finanças e empresas, típicas dos insiders; de outro, governo, terceiro setor, academia e organizações internacionais, características dos outsiders. O capital simbólico refere-se à fama, à reputação, ao prestígio (cf. Bourdieu, 1994, p. 134) e é expresso pela obtenção de prêmios e por publicaçōes (livros, artigos em jornais ou revistas, participação como palestrante em conferências). O capital social refere-se ao conjunto de recursos atuais e potenciais que dependem da participação em uma rede durável mais ou menos conhecida e renomada institucionalmente (cf. Bourdieu, 1980). Pertencer a uma rede duradoura pode ser considerado um passo para a obtenção de lucros materiais e simbólicos. No espaço social 
em questão, o capital social refere-se à quantidade de posições ocupadas em outras organizações.

Análise dos dados e algumas considerações

\section{Trajetória educacional}

Como o ISR é uma interface recente entre o espaço das finanças e o do desenvolvimento sustentável, a trajetória educacional pode variar de um polo (aquele dos estudos sobre finanças e negócios) para outro (aquele sobre estudos em humanidades ou biológicas). No meio deste continuum, podemos encontrar uma mistura dessas duas trajetórias.

QUADRO 1

Formação educacional

\begin{tabular}{c|c|c|c}
\hline \hline ÍNDICE/PAís & NeGÓCIOS & INTERFACE & HuMANIDADES/BIOLÓGICAS \\
\hline \hline \multirow{2}{*}{ FTSE4Good/Inglaterra } & CR & EK & TD \\
\hline \multirow{2}{*}{ SRI/África do Sul } & AB & CM & TF \\
& DJ & MG & NK \\
& KI & & ZL \\
& CC & & \\
ISE/Brasil & RN & LM & LK \\
& PM & & WM \\
& RY & & JE \\
\hline \hline
\end{tabular}

Obs.: Quadro adaptado de resultado obtido por meio do programa SPss.

Fonte: Dados biográficos reunidos para esta pesquisa. As siglas referem-se às iniciais dos nomes dos atores sociais considerados.

Em meio à variedade de diplomas - economia, administração, arquitetura, engenharia civil, direito, psicologia, ciências sociais, geologia e até mesmo microbiologia -, existe um ponto em comum: a maior parte dos conselheiros estudou nas melhores universidades de seus países, o que os caracteriza como grupo de elite. No entanto, quando inserimos essas profissões em um continuum, é possível verificar que a trajetória educacional é bem-distribuída de maneira geral, excetuando-se o Brasil com uma concentração maior na trajetória dos negócios. 
Desse modo, o Quadro 1 mostra que, em sua maioria, os conselheiros têm uma formação homogênea ${ }^{5}$ e clássica, ou em ciências biológicas ou na área de negócios ou de humanidades. Embora não tenha sido fácil encontrar informaçôes sobre a trajetória educacional de quase metade dos conselheiros da África do Sul e da Inglaterra, não houve tanta dificuldade em mapear os locais de suas atuações profissionais, bancos ou empresas, em sua maioria.

5. Considero homogênea aquela formação em que graduação e pós-graduação foram realizadas dentro de uma mesma área de concentração: humanas, biológicas ou negócios. Isso pode indicar que eles não são externos aos negócios ou às finanças e sim insiders, que não precisam converter o próprio capital para falar de sustentabilidade e finanças.

Porém, cinco desses atores nos chamam a atenção por situarem-se entre esses opostos. As trajetórias deles são mistas, ou seja, possuem formação educacional em áreas distintas entre si e talvez possam apontar para uma trajetória típico-ideal nessa esfera de interseção entre finanças e sustentabilidade.

QUADRO 2

Membros tipo-ideal

\begin{tabular}{|c|c|c|c|c|c|}
\hline$\tilde{I}_{\text {NDICE }}$ & EDUCAÇĀO & UNIVERSIDADE & CARREIRA & $\begin{array}{l}\text { CAPITAL } \\
\text { SOCIAL } \\
\end{array}$ & $\begin{array}{c}\text { CAPITAL } \\
\text { Simbólico } \\
\end{array}$ \\
\hline DJSI & $\begin{array}{l}\text { Economia, geografia e es- } \\
\text { tudos em desenvolvimento }\end{array}$ & $\begin{array}{l}\text { Universidade da Califórnia, em } \\
\text { Los Angeles }\end{array}$ & $\begin{array}{l}\text { Finanças e Organização } \\
\text { Não Governamental }\end{array}$ & TBLI & Alto \\
\hline FTSE4Good & Historia da Ciência & $\begin{array}{l}\text { Universidade de Brown/Fletcher } \\
\text { School of Law and Diplomacy }\end{array}$ & Finanças e Academia & Alto & Alto \\
\hline FTSE4Good & $\begin{array}{l}\text { Ciências Sociais e Adminis- } \\
\text { tração Ética }\end{array}$ & Universidade de Durham/ Bath & Finanças e Academia & TBLI/ GRI & Alto \\
\hline JSE ISR & $\begin{array}{l}\text { Hidrologia e Ciências e } \\
\text { Direito Ambiental }\end{array}$ & Universidade de Natal & Finanças- Finanças & Baixo & Baixo \\
\hline ISE & $\begin{array}{l}\text { Engenharia Civil e Ne- } \\
\text { gócios }\end{array}$ & $\begin{array}{l}\text { Universidade Mackenzie e Thun- } \\
\text { derbird University }\end{array}$ & Finanças-Finanças & TBLI & Baixo \\
\hline
\end{tabular}

Fonte: Perfis na página do Triple Bottom Line Conference ou em páginas eletrônicas. O banco de dados desta pesquisa está arquivado.

Dois perfis gerais podem ser extraídos desses cinco membros: os atores do Norte, ou seja, conselheiros dos Estados Unidos e da Inglaterra, têm uma trajetória educacional mais "heterodoxa", isto é, não se formaram em negócios ou finanças, ainda que trabalhassem nessas áreas. Um deles segue para o terceiro setor, enquanto o outro se muda para a área acadêmica. A mudança das finanças para o terceiro setor ou para a academia foi acompanhada por diversas publicações, prêmios e apresentações na conferência do Triple Bottom Line Investing (TBLI), na qual os líderes de ISRs são convidados a se pronunciarem. Isso quer dizer que, como eles passam a circular em espaços 
sociais diferentes, para tornarem-se líderes e entrarem para o conselho de um indicador são necessários informações biográficas acessíveis e um alto grau de capital simbólico e social. Esse caso pode sugerir trajetória profissional se sobrepondo à trajetória educacional.

O outro perfil corresponde aos conselhos do Sul, ou seja, Brasil e África do Sul. Além de terem uma "folha" como logotipo de seus indicadores, estes membros, apesar de terem uma educação "heterodoxa", começaram a trabalhar com ISR a partir do momento em que passaram a atuar nos mercados financeiros: um em uma gestora de recursos e outro em um banco comercial. A diferença em relação aos colegas do Norte é a de que eles permanecem na esfera das finanças. Como nenhum migrou para outros espaços sociais (academia, terceiro setor), não tiveram que converter seus capitais nem em capital simbólico nem em capital social. Provavelmente, a reputação desses dois indivíduos foi construída e é inerente aos jogos da esfera financeira.

Esse caso é significativo para a formulação da hipótese de que, de maneira geral, a formação educacional mostra que aqueles que têm um diploma em área considerada "heterodoxa", para estarem aptos a se pronunciarem sobre sustentabilidade e finanças, precisam fazer se esforçar para converterem seu capital educacional em capital simbólico. Aqueles com trajetória na área de finanças não o fazem.

Uma característica comum a esses cinco atores é o fato de trabalharem diretamente com o ISR, o que os torna o nosso "tipo ideal".

\section{Trajetória profissional}

Conforme os dados do Quadro 3, a maior parte dos membros dos conselhos tem trajetória profissional nos negócios privados, excetuando-se quatro que agem como força de equilíbrio e como atores-chave para a atribuição, aos comitês, de alto grau de representatividade dos diversos interesses presentes nos conselhos. Os números representam uma trajetória de negócios (0), financeira (1), financeira para outras (2-3), governamental/política (4) e organizaçōes internacionais que não trabalham com ISR (5).

Como podemos ver, a maioria concentra-se numa trajetória financeira e de negócios. Brasil e Inglaterra têm a maior parte dos membros que trabalham na esfera financeira, enquanto a África do Sul, em negócios. 
QUADRO 3

Trajetória profissional

\begin{tabular}{|c|c|c|}
\hline IÍNDICE/PaÍs & COMEÇOU NA ESFERA FINANCEIRA & COMEÇOU NA ESFERA PÚBLICA \\
\hline 更 & $\begin{array}{l}\mathrm{TD} \\
\mathrm{MP} \\
\mathrm{AB} \\
\mathrm{CS} \\
\mathrm{SW} \\
\mathrm{JM} \\
\mathrm{MA} \\
\mathrm{CM} \\
\mathrm{EK}\end{array}$ & $\mathrm{CR}$ \\
\hline 更 & $\begin{array}{l}\text { WP } \\
\text { RN } \\
\text { KI } \\
\text { ZL } \\
\text { TD } \\
\text { CM } \\
\text { MG } \\
\text { NK } \\
\text { TF } \\
\text { DJ }\end{array}$ & $\mathrm{ZC}$ \\
\hline ISE/Brasil & $\begin{array}{l}\mathrm{RY} \\
\mathrm{RN} \\
\mathrm{RG} \\
\mathrm{LM} \\
\mathrm{PM}\end{array}$ & $\begin{array}{l}\text { LK } \\
\text { CC }\end{array}$ \\
\hline DJSI/Estados Unidos & $\begin{array}{l}\text { JE } \\
\text { WM } \\
\text { BJ } \\
\text { MC }\end{array}$ & - \\
\hline
\end{tabular}

Obs.: Quadro adaptado de resultado obtido por meio do programa sPss.

Fonte: Dados biográficos reunidos para esta pesquisa. As siglas referem-se às iniciais dos nomes dos atores sociais considerados.

A par da elaboração do ISE, desenvolveu-se um debate ideológico sobre o papel das companhias (especialmente aquelas listadas na Bovespa) no conselho relativo ao indicador. Esse debate resultou na impossibilidade de as companhias serem conselheiras do ISE. Isso não ocorre na África do Sul, que integra algumas listed companies a seu conselho. Por que o Brasil exclui companhias do conselho, enquanto a África do Sul segue em direção oposta?

Primeiramente, isso pode representar uma diferença ideológica entre sul-africanos - que identificam o ISR como parte do movimento da responsabilidade social empresarial - e brasileiros - que querem dar mais autonomia 
ao ISR. No Brasil, é possível observar uma divisão entre os executivos que desejam definir o que é a responsabilidade social empresarial e os profissionais do mercado financeiro, investidores e acionistas, que querem criar o seu próprio domínio do social, o ISR.

A atuação dos conselheiros pode ser dividida em um polo de finanças e outro de responsabilidade social. Assim, em termos de atuação de seus conselheiros, o índice da África do Sul estaria mais próximo dos valores inerentes à responsabilidade social das empresas, enquanto os índices brasileiro e inglês estariam mais próximos às finanças sustentáveis. Ao considerar o lado direito do Quadro 3, localizamos três conselheiros que estão fora tanto da trajetória de negócios quanto da financeira. $\mathrm{O}$ índice brasileiro conta com dois atores representantes do meio ambiente. Um vem do governo, tem filiação política de esquerda explícita e não tem passagem pela esfera financeira; o outro vem de uma agência das Organizaçōes das Naçôes Unidas e pretensamente representa o meio ambiente também. Nenhum deles apresenta o tema do ISR de maneira explícita em sua minibiografia.

O conselho da África do Sul tem um membro que apresenta uma trajetória peculiar: ele não pôde pagar por uma educação universitária e começou a agir na esfera política pela defesa dos negros, especialmente durante o período do Apartheid. Envolveu-se com o ISR por meio de suas conexôes no campo político. Como explicitado anteriormente na breve história do ISR, este deve à África do Sul parte de seu desenvolvimento, fato que coloca um partido político com aspirações socialistas entre as instituições privadas e financeiras que compóem o conselho sul-africano. Assim, ambos os conselhos do Sul parecem incorporar indivíduos de dois polos opostos (privado e público). Em países com cenário de lutas políticas, parece que incorporar polos opostos se torna necessário para atribuir o status de neutralidade aos conselhos.

Em termos de representatividade, Brasil e África do Sul parecem apresentar maior variedade de interesses, mas um olhar analítico mais aprofundado detecta que as trajetórias educacional e profissional os classificam como parte de uma mesma ideologia dominante. Dessa maneira, a constituição de lieu neutre dos conselhos é pautada pelas características associadas ao domínio do conhecimento com relação à sustentabilidade que, por definição, engloba diferentes públicos interessados. No entanto, a maior parte dos conselheiros possui graduação ou passagem profissional na área de negócios, o que demonstra a preponderância dos esquemas de classificação do mundo empresarial e das finanças sobre a classificação das empresas em termos de sustentabilidade. 
Ideologia

No intuito de compreender as ideias norteadoras dos conselhos, é necessário identificar se eles se relacionam com alguma instituição em comum, o que pode indicar alto grau de capital social entre os membros desses órgãos. Cada membro participa de uma variedade de instituições nos papéis de diretor, de associado ou de diretor não executivo. Mas, a SustainAbility, firma de consultoria internacional, está presente em todos os conselhos. De fato, a ideia de que a empresa deve se preocupar com o planeta, com a sociedade e com o lucro, conhecida como Triple Bottom Line (TBL) e criada pela consultoria, serviu como orientação para a construção dos indicadores brasileiro e sul-africano. Os conselheiros com cadeira na SustainAbility têm uma trajetória profissional marcada pela esfera dos negócios. O caso do Global Reporting Initiative (GRI) - um modelo internacional de prestação de contas em termos de sustentabilidade utilizado pelos quatro conselhos - é o mesmo, ou seja, é a instituição que marca os quarto conselhos, contando com associados na África do Sul, Brasil, Estados Unidos e Inglaterra. Esses dois think tanks internacionais moldam as ideias sobre o ISR e ajudam a criar uma linguagem comum que une todos esses diferentes conselheiros de diferentes países.

O conceito de TBL desenvolvido pela SustainAbility influenciou os índices do Norte e do Sul, sendo que os conselheiros do Sul o incorporaram às ideias de governança corporativa. Como, por exemplo, o Brasil, que seguiu o exemplo da África do Sul nesse tipo de combinação. Porém, o indicador brasileiro procura distinguir-se ao incluir, em sua metodologia, uma consulta pública com o intuito de associar o ISR às diretrizes da democracia. A aceitação do conceito criado pela SustainAbility indica a influência relevante da ideia de sustentabilidade na Europa, particularmente na Inglaterra, onde surgiu tal consultoria.

\section{Comentários finais}

As complexidades que concernem à criação de um novo mercado são inerentes ao processo de sua criação. Esse exercício de sociologia acerca dos profissionais que participam dos conselhos dos índices de sustentabilidade das bolsas de valores indicou alguns insights para a compreensão da lógica que une finanças e sustentabilidade em uma abordagem global.

Para a inserção dos insiders em outras esferas (pública, acadêmica), é necessário que estes convertam seu capital financeiro em capital simbólico. 
Além disso, todos os índices são marcados por uma ideologia específica do GRI e do SustainAbility. A formação educacional dos conselheiros não aparenta ser determinante para sua participação nos conselhos, apesar de a maioria ter estudado em cursos da esfera dos negócios e das finanças. Mas o que aparenta ser mais determinante para a ocupação de uma cadeira nesses conselhos é a passagem profissional pela esfera financeira. Daqueles que já pertenciam a ela, não se requer reconversão de capital.

Quanto à representatividade e ao lieu neutre, mesmo com diferenças nacionais referentes às trajetórias profissionais dos líderes e à representatividade dos índices sulistas, uma trajetória profissional pelas finanças, o compartilhamento das ideias divulgadas pela SustainAbility e pelo GRI e a participação de profissionais outsiders nos conselhos do Sul aparentam compor a lógica que rege a imbricação entre finanças e sustentabilidade. Excetuando-se os conselhos da África do Sul, os dos demais países criam uma dualidade entre as empresas, por eles julgadas e classificadas, bem como os próprios atores capazes da classificá-las. Parece que o movimento em favor do ISR, que surgiu a partir da crescente institucionalização das práticas de responsabilidade social empresarial, tenta seguir os próprios passos.

Não tenho intenção de reduzir o fenômeno da inserção da sustentabilidade no âmbito das finanças ao espaço dos conselhos de sustentabilidade dos índices. Este trabalho é um exercício cujo intuito é estimular a sociologia a olhar para os índices como objetos de estudo, no sentido de desenvolvermos uma sociologia dos índices.

Enquanto o mundo ainda estava em crise no final de 2008, o Dow Jones Sustainability Index recebeu a notícia de que ele seria o referencial que orientaria os investimentos de um fundo mútuo e também em investimentos de mercado de futuros. A crescente aprovação do indicador indica confirmação, por aqueles que pertencem a seus conselhos, da posse dos capitais necessários para criar novos esquemas de classificação para que o mundo financeiro oriente a si mesmo e a todos nós. Como diferentes esferas têm adotado índices de sustentabilidade, a análise sociológica pautada na ideia de evaluation practices (Mackenzie, 2010, p. 7) pode revelar novas configurações da relação entre sociedade e mercado financeiro. Ou seja, a ascensão de índices de sustentabilidade representa a disposição dos diferentes setores em incorporar esse tema a uma linguagem universalmente aceita e reconhecida: a linguagem numérica. No entanto, a construção desses índices não representa apenas a produção de recursos de medição, mas também a criação de ferramentas de poder e de representações sobre a realidade social. 


\section{Referências Bibliográficas}

Bourdieu, Pierre. (1980), "Le capital social". Actes de la recherche en sciences sociales, Paris, 31(31): 2-3, janeiro. (1994), O poder simbólico. Rio de Janeiro, Bertrand Brasil. (1986), "Lillusion biographique". Actes de la recherche en sciences sociales, Paris, 62-63: 69-72, jun.

Bourdieu, Pierre \& BolTANSKi, Luc. (1976), "La production de l'ideologie dominante”. Actes de la recherche en sciences sociales, Paris, 2-3(2): 4-76, jun.

Brito, Cesar de; Desmartin, Jean-Philippe; Lucas-Leclin, Valéry \& Perrin, François. (2005), L'investissement socialement responsable. Paris, Economica.

Centro de Estudos de Sustentabilidade. (2010), “Finanças sustentáveis”. Disponível em <http://ces.fgvsp.br/gvces/index.php?page=Conteudo\&id=25>, consultado em 30/11/2010.

DÉJEAN, Fréderic. (2005), L’investissement socialement responsable: étude du cas français. Paris,Vuibert.

DJSI. (2008), “Dow Jones Sustainability World Indexes Guide. Version 10.1”. Disponível em <http://www.sustainability-index.com/djsi_pdf/publications/Guidebooks/ DJSI_World_Guidebook_10_1.pdf>, consultado em 6/1/2009.

Dow Jones. (2008), "Dow Jones sustainability world index licensed for U.S.-based Mutual fund for the first time". Disponível em <http://www.sustainability-index. com/djsi_pdf/news/PressReleases/DJSI_PressReleases_081218_Dreyfus.pdf $>$, consultado em 30/11/2010.

EUROSIF. (2008), “European SRI Study”. Disponível em <http://www.eurosif.org/media/ files/eurosif_sristudy_2008_global_01>, consultado em 21/6/2010.

FTSE. (2008), "Index Rules”. Disponível em <http://www.ftse.com/Indices/fTSE4Good_Index_Series/Index_Rules.jsp $>$, consultado em 6/1/2009.

GIAMPORCARO, Stéphanie. (2006), Linvestissement socialement responsable - entre l'offre et la demande: analyse et enjeux de la construction sociale d'une épargne politique. Paris, tese de doutorado, Université René Descartes Paris v.

GoEdE, Marieke. (2005), Virtue, fortune and faith: a genealogy of finance. $1^{\mathrm{a}}$ edição 1971. Minneapolis, Borderlines Series.

Gond, Jean-Pascal. (2006), “Construire la relation (positive) entre performance sociétale et performance financière: de la performativite a autoréalisation?”. Revue d'Economie Financière, 85 (4): 63-79.

Immelt, J. (2008), "Plenary Session Summary. Business for social responsibility Conference 2008". Disponível em <http://www.google.com.br/url?sa=t\&rct=j\&q=\&esrc =s\&frm=1\&source=web\&cd=1\&cad=rja\&ved=0CCIQFjAA\&url=http $\% 3 \mathrm{~A} \% 2 \mathrm{~F} \% 2 \mathrm{~F}$ 
www.bsr.org\%2Fpdfs\%2Fbsr-conference\%2F2008\%2FBSR_Conf2008_GE_Plenary. pdf\&ei=1-1MUIy0Iaat0AG4mIDgAg\&usg=AFQjCNE3Id3rC00wMMXihRlbTfu0vC4 7TQ>, consultado em 9/9/2012.

JSE. (2008), "Criteria”. Disponível em <http://www.jse.co.za/About-Us/sRI/Criteria. aspx>, consultado em 30/11/2010.

LÉBARON, Frédéric. (2008). "Central bankers in the contemporary global Field of Power: a social space approach”. In: SavaGe, Mike \& Williams, Karel. Remembering elites. Oxford, Blackwell, pp. 121-144.

Mackenzie, Donald. (2010). "The credit crisis as a problem in the sociology of knowledge". Working Paper. Disponível em <http:/www.sps.ed.ac.uk/_data/ assets/pdf_file/0019/36082/CrisisRevised.pdf>, consultado em 4/11/2010.

SARTORE, Marina de Souza. (2010), Convergência de elites: a sustentabilidade no mercado financeiro. São Carlos, tese de doutorado, Universidade Federal de São Carlos.

Social Investment Forum. (2007), "Report on Socially Responsible Investing trends in the United States". Disponível em <http://www.socialinvest.org/pdf/sRI_Trends_ExecSummary_2007.pdf>, consultado em 21/6/2010.

Twin, Alexandra. (2008), “Stocks Crushed. CNN Money. 29/09/2008”. Disponível em <http://money.cnn.com/2008/09/29/markets/markets_newyork/index.htm>, consultado em 10/1/2009.

VAlenti, Graziela \& ToRRES, Fernando. (2010), "Bolsa reavalia sustentabilidade”. Valor Econômico, 1/3/2010. Disponível em <https://conteudoclippingmp.planejamento. gov.br/cadastros/noticias/2010/3/1/bolsa-reavalia-sustentabilidade/>, consultado em 21/6/2010.

\section{Resumo}

A sociologia dos índices de sustentabilidade

O colapso sofrido pela sociedade financeira com a crise dos subprimes em 2008 criou uma atmosfera desafiadora e favorável para o desenvolvimento de novas teorias e abordagens do sistema financeiro. Esse ambiente permite indagar sobre as possíveis ferramentas sociais e econômicas postas em prática para reerguê-lo. As práticas de Investimento Socialmente Responsável (ISR) podem ser uma delas. Alguns analistas financeiros buscam sobreviver ao ocaso de velhas práticas por meio da consideração de critérios sociais, ambientais e econômicos no momento de investir ou conceder crédito. Partindo da sociologia econômica, este artigo sugere as bases para uma investigação sobre quem são estes atores sociais que trabalham para instituir uma interface entre finanças e sustentabilidade, ou ainda, que se esforçam para criar um mercado financeiro sustentável. Explora esta questão no plano internacional, considerando os conselhos dos índices de sustentabilidade do mercado de ações no Brasil (ISE), nos Estados Unidos (DJSI), na 
Inglaterra (FTSE4Good) e na África do Sul (JSE SRI) como espaços sociais que evidenciam características sociológicas daquela interface. A conclusão do artigo apresenta uma análise comparativa entre estes conselhos, constituídos, por sua vez, simultaneamente pela lógica do lieu neutre e pelas particularidades dos países que representam.

Palavras-chave: Investimento socialmente responsável; Conselhos; Sociologia econômica.

\section{Abstract}

\section{The sociology of sustainability indices}

The collapse in the financial markets caused by the subprime crisis in 2008 created a challenging and favorable atmosphere for the development of new sociological theories and approaches to studying the financial system. Although every sub-space of finance was badly affected, Socially Responsible Investing shows evidence of new solutions to the crisis. Some financial analysts now look to avoid the shrinkage faced by older investing practices by taking environmental, social and economic criteria into account at the moment of the investment. Adopting an approach based on economic sociology, this article offers the initial bases for a study about these social actors who have been forcefully working to create an interface between finance and sustainability, or in other words, a Sustainable Financial Market. The article explores this issueat international level by considering the North American, British, Southern African and Brazilian Corporate Sustainability Index Committees, which can be seen as social spaces in which the sociological characteristics of this interface become apparent. The article concludes by presenting a comparative study of these committees, which are constituted by lieu neutre (neutral ground) logic as well as by the particularities of the countries that they each represent.

Keywords: Socially responsible Investing; Committees; Economic sociology.

Texto recebido em 1/10/2010 e aprovado em 6/8/2012.

Marina de Souza Sartore é pesquisadora do Núcleo de Sociologia Econômica e das Finanças (Nesefi) da Universidade Federal de São Carlos. E-mail: <marina. ufg@gmail.com>. 